\title{
OPTIMASI DAN IDENTIFIKASI PARAMETER KRITIS PADA PROSES EXTRUSION MENGGUNAKAN METODE TAGUCHI
}

\section{THE OPTIMIZATION AND IDENTIFICATION OF THE CRITICAL PARAMETER OF EXTRUSION PROCESS BY USING TAGUCHI METHOD}

\author{
Kemas Muhammat Abdul Fatah \\ Program Studi Teknik Mesin Universitas Sang Bumi Ruwa Jurai \\ Jalan Imam Bonjol No. 468 Langkapura, Bandar Lampung, (0721)257838 \\ E-mail: kmsmafattah@gmail.com
}

Diterima: $12-10-2020$

Direvisi: 3-11-2020

Disetujui: 23-12-2020

\begin{abstract}
ABSTRAK
PVC Conduit atau pipa listrik PVC diproduksi menggunakan teknologi ekstrusi dengan bagian utamanya adalah barre/ dengan setting temperatur dan kecepatan screw yang disesuaikan dengan materialnya, perubahan material akan berdampak pada perubahan setting mesin. Penelitian ini bertujuan untuk mendapatkan setting mesin yang paling optimal atas perubahan material dan mengidentifikasi parameter kritis yang mempengarui proses di dalam barre/ yang berdampak pada degradasi mutu material. Metode Taguchi $\mathrm{L} 27\left(3^{5}\right)$ dengan respon hasil uji beban kejut (impact test) dan desain parameter (factor) terdiri dari temperatur barrel area 1 (faktor A), temperatur barrel area 2 (faktor B), temperatur barrel area 3 (faktor C), temperatur barrel area 4 (faktor D), dan kecepatan screw (faktor E), dengan masing-masing terdiri 3 level. Dari perhitungan $\mathrm{S} / \mathrm{N}$ ratio diperoleh parameter optimal yaitu $190^{\circ} \mathrm{C}$ untuk faktor $\mathrm{A}, 200^{\circ} \mathrm{C}$ untuk faktor $\mathrm{B}, 160^{\circ} \mathrm{C}$ untuk faktor $\mathrm{C}, 175^{\circ} \mathrm{C}$ untuk faktor $\mathrm{D}$ dan $15 \mathrm{RPM}$ untuk faktor $\mathrm{E}$, dapat disingkat menjadi $A_{3} B_{3} C_{1} D_{2} E_{2}$. Sementara itu, dari analisis Anova dapat diidentifikasi bahwa faktor $C$ atau temperatur barre/ area 3 menjadi parameter yang kritis, perubahan pada temperatur akan berdampak pada perubahan karakteristik proses yang terjadi di dalam barrel, baik pada zona mixing atau zona metering atau pada keduanya.
\end{abstract}

Kata kunci: barrel, extrusion, metode Taguchi, PVC conduit

\begin{abstract}
The extrusion process is a process for the production of PVC ducts and the barrel is the main component in which the temperature adjustment and the speed of the screw depend on the raw material, the change would be followed by a change of adjustment. The objective of this analysis was to optimize the setting parameter and to define important parameters that would have an impact on the process in the barrel relevant to material quality degradation. Taguchi process $L_{27}\left(3^{5}\right)$ with reaction effect test and barrel temperature 1st area (factor $A$ ), barrel temperature 2nd area (factor B), barrel temperature 3rd area (factor C), barrel temperature 4th (factor D) and screw speed (factor E) were in the specification parameter and had 3 levels of each. The SN ratio equation found the value of the optimization parameter, $1900 C$ for the factor $A, 2000 C$ for the factor $B, 1600 C$ for the factor $C, 1750 C$ for the factor $D$ and $15 R P M$ for the factor $E$. The analysis of the variant (ANOVA) established that the factor $C$ or the barrel temperature $3 r d$ region was a crucial parameter to adjust the temperature would have an effect on the process in the barrel, either in the mixing zone or in the meter zone or both.
\end{abstract}

Keywords: barrel, extrusion, PVC conduit, Taguchi method 


\section{Pendahuluan}

D ipa instalasi listrik atau pipa konduit (electrical conduit) berfungsi untuk melindungi dan mengarahkan kawat pengantar dalam instalasi listrik. Ada beberapa jenis dari pipa listrik, salah satunya adalah tipe PVC Conduit dimana bahan baku utamanya adalah polyvinyl chloride (PVC) yang memiliki sifat utama tidak menghantarkan panas, tidak mudah terbakar, nyala api akan mati dengan sendirinya, sehingga digunakan secara luas pada sektor konstruksi (Magnago et al., 2017).

Terdapat beberapa merek PVC conduit yang beredar di Indonesia, diantaranya adalah merek Boss, Clipsal dan Legrand, dengan produsen yang berbeda. Banyaknya produsen PVC conduit tentu saja memunculkan kompetisi diantara perusahaan tersebut di dalam memperebutkan pangsa pasar. Untuk dapat unggul dalam berkompetisi maka perlu bagi perusahaan menjalankan strategi yang tepat sehingga kompetisi dapat dimenangkan, salah satu strategi yang dapat dipilih adalah strategi kepemimpinan biaya rendah (Fatah, 2020) yang bertujuan untuk meningkatkan pangsa pasar berdasarkan menciptakan posisi biaya rendah dibandingkan dengan perusahaan sejenis (Banker et. al., 2014).

Di dalam menjalankan strategi kepemimpinan biaya rendah dimana perusahaan berusaha untuk mendapatkan tingkat efisiensi tertingi dan biaya terendah, salah satu cirinya adalah meminimalisasi biaya pada semua aktifitas di dalam rantai nilai (Natalia, 2019), termasuk didalamnya adalah aktifitas perbaikan (improvement) terhadap bahan baku yang digunakan, dengan merancang formulasi bahan baku sehingga tercapai biaya yang lebih rendah.

Di dalam memproduksi PVC conduit, formulasi bahan bakunya terdiri atas PVC resin, filler dan additives (stabilizer, release agent, lubricant, UV radiation protection, anti-impact modifier). Pada penelitian ini, akan dilakukan modifikasi bahan baku sehingga formulasi bahan baku hanya terdiri dari PVC resin, filler, UV radiation protection dan one pack additives. Perbedaan dari kedua formulasi bahan baku pada setiap $100 \mathrm{~kg}$ resin PVC dapat dilihat pada Tabel 1.

Tampak dari Tabel 1, perubahan formulasi bahan baku adalah dengan penambahan one pack additives pada formulasi riset yang menggantikan beberapa komponen additives pada formulasi lama, dengan perubahan formulasi bahan baku akan terjadi efisiensi biaya (saving) sebesar 6,8 \%. Selain itu, penggunaan one pack additives juga lebih mudah dalam penanganan material, proses pencampuran lebih cepat, konsistensi produk juga ditingkatkan karena berkurangnya jumlah bahan yang perlu ditimbang, suatu pekerjaan yang biasanya harus dilakukan dengan tangan dan oleh karena itu lebih rentan terhadap kesalahan manusia (Holsopple, 1993).

Proses produksi PVC conduit menggunakan teknologi ekstrusi yaitu proses manufaktur yang menggunakan mesin ekstruder yang dilengkapi dengan parameter setting mesin, seperti resin temperature, resin pressure, resin moisture content, barrel temperature, screw speed, screw motor amperage, quenching temperature dan take-off speed. Nilai dari setiap parameter setting mesin untuk material yang akan diproses adalah penting untuk diketahui karena terkait dengan karakteristik produk akhir yang dihasilkan (González-Seligra et al., 2017). Perubahan material pada formulasi penelitian, tentu akan diikuti perubahan beberapa nilai parameter setting mesin, sehingga diperlukan desain eksperimen (DOE) untuk mendapatkan parameter proses yang optimal.

DOE pada awal diperkenalkan pada tahun 1920-an dengan jumlah banyaknya eksperimen dilakukan mengikuti metode ekperimen full-factorial, metode ini dinilai tidak efisien sehingga pada tahun 1940-an disempurnakan lagi dengan metode orthogonal arrays, sampai pada 
akhirnya, pada tahun 1950-an Genichi Taguchi berhasil mengaplikasikan DOE dan orthogonal arrays (Rao et al., 2013) sehingga menjadi salah salah satu teknik DOE yang digunakan untuk optimalisasi parameter proses (Alafaghani dan Qattawi, 2018), salah satu metode yang paling umum digunakan (Moralı et. al., 2018) karena secara efektif dapat menurunkan jumlah eksperimen yang dibutuhkan (Chen et. al., 2017).

Tabel 1. Biaya formulasi bahan baku

\begin{tabular}{lcc}
\hline Bahan baku & Formulasi Lama & Formulasi Riset \\
\hline Biaya : & 120 & \\
- PVC resin & 0,90 & 120 \\
- Filler & 14,70 & 3 \\
- Stabilizer & 1,24 & - \\
- Release agent & 10,4 & - \\
- Lubricant & 9,60 & - \\
- UV radiation protection & 3,2 & 7,5 \\
- anti-impact modifier & - & - \\
- One pack additives & 160,04 & 40,15 \\
- Total & 116,70 & 170,65 \\
\hline Berat formulasi $(\mathrm{kg})$ & 1,371 & 170,65 \\
\hline Biaya satuan $(\$ / \mathrm{kg})$ & \multicolumn{3}{c}{6,278} \\
\hline Efisiensi &
\end{tabular}

Metode Taguchi banyak digunakan di dalam penelitian, diantaranya pada proses produksi synthetic lightweight aggregate (Chen et. al., 2017), pada produksi laccase Marasmiellus palmivorus (Chenthamarakshan et al., 2017), pada proses produksi binder jetting (Shrestha dan Manogharan, 2017), pada perancangan permanent magnet linear (Song et al., 2017) pada proses pengelasan TIG (Balaram Naik dan A. Chennakeshava, 2018), proses CNC end milling (Pang et al., 2014), pada proses Injection Molded Polystyrene (Yizong et al., 2017). Dari beberapa penelitian seperti yang dikutip di atas, tampak bahwa metode Taguchi secara luas digunakan untuk menemukan parameter proses yang optimal dan dapat digunakan pada berbagai proses manufaktur.

Desain eksperimen metode Taguchi dimulai dari memilih fungsi tujuan atau variabel respon dan desain parameter (Khanna dan Davim, 2015). Nilai variabel Respon dapat dikaitkan dengan hasil pengukuran mutu produk (Balaram Naik dan A. Chennakeshava, 2018) dan nilai variabel desain parameter dapat ditentukan mengacu pada nilai dari faktor-faktor yang mempengaruhi karakteristik mutu pada proses manufaktur (Pang et al., 2014). Terkait dengan proses extrusion, beberapa penelitian terdahulu yang menggunakan DOE metode Taguchi, menetapkan respon dan desain parameter yang berbeda-beda. Misalnya, respon dapat berupa mutu produk yang diukur dari tahan terhadap tekanan (Sharma et al., 2017), mutu produk yang diukur dari ketebalan (Gadekar et al., 2015; Solomon et al., 2016), mutu produk yang diukur dari kekuatan tarik (Joshi dan Goyal, 2018). Sementara itu, desain parameter dapat dapat terdiri dari feeding zone temperature, melting zone temperature, pushing zone temperature, dimmer speed, die head temperature (Sharma et al., 2017), atau terdiri dari zones temperature dan take-off speed (Gadekar et al., 2015), atau terdiri dari feed drum heat, core heat dan mold heat (Solomon et al., 2016), atau juga terdiri dari extrusion pressure, melting temperature, winder speed dan extruder speed (Joshi dan Goyal, 2018). 
Di dalam penelitian ini, parameter yang dipilih sebagai faktor adalah nilai setting temperatur barrel $\left({ }^{\circ} \mathrm{C}\right)$ dan kecepatan screw (RPM), dengan rasionalisasi bahwa dengan adanya penambahan persentase $\mathrm{CaCO}_{3}$ pada formulasi riset akan menurunkan nilai Melt Flow Rate (Jiang et al., 2018)[23] dan perubahan MFR akan diikuti oleh perubahan temperatur (Liang et al., 1999). Dengan demikian, setting temperatur dan kecepatan screw akan mempengaruhi proses di barrel, pemilihan nilai parameter yang tidak tepat dapat mempengaruhi mutu material (molten) yang berdampak pada mutu PVC conduit.

Dari gambaran mengenai pengaruh parameter temperatur barrel dan kecepatan screw terhadap mutu PVC conduit, penelitian ini ditujukan untuk menentukan kombinasi variasi parameter yang optimal dengan menggunakan metode Taguchi dan mengidentifikasi parameter kritis yang mempengaruhi mutu PVC conduit.

\section{METODE PENELITIAN}

Formulasi riset pada panelitian ini menggunakan calcium carbonate $\left(\mathrm{CaCO}_{3}\right)$ sebagai material filler dengan porsi lebih banyak pada $100 \mathrm{~kg}$ resin $\mathrm{PVC}$, dan penggunaan $\mathrm{CaCO}_{3}$ akan meningkatkan kekuatan beban kejut (Jiang et al., 2018) dan ketahanan terhadap beban kejut merupakan salah satu karakteristik mutu pipa conduit yang disyaratkan menurut BS EN 613861: 2008 (BS EN, 2008). Oleh karenanya, sebagai variabel respon pada penelitian ini adalah kekuatan beban kejut.

Parameter yang dipilih sebagai faktor di dalam penelitian ini adalah nilai setting temperatur barrel $\left({ }^{\circ} \mathrm{C}\right)$ yang terdiri dari 4 area, yaitu temperatur barrel area 1 (faktor $\mathrm{A}$ ), temperatur barre/ area 2 (faktor B), temperatur barre/ area 3 (faktor C), temperatur barre/area 4 (faktor D). Faktor yang lain adalah kecepatan screw (faktor E). Masing-masing level untuk setiap faktor dapat dilihat pada Tabel 2 di bawah ini.

Tabel 2. Faktor dan level

\begin{tabular}{ccccc}
\hline & \multirow{2}{*}{ Faktor } & \multicolumn{3}{c}{ Level } \\
\cline { 3 - 5 } & & 1 & 2 & 3 \\
\hline A & Temp. Barel Area 1 $\left({ }^{\circ} \mathrm{C}\right)$ & 190 & 185 & 190 \\
B & Temp. Barel Area 2 $\left({ }^{\circ} \mathrm{C}\right)$ & 190 & 195 & 200 \\
C & Temp. Barel Area 3 $\left({ }^{\circ} \mathrm{C}\right)$ & 165 & 175 \\
D & Temp. Barel Area 4 $\left({ }^{\circ} \mathrm{C}\right)$ & 14 & 175 & 180 \\
E & Kecepatan screw (RPM) & 15 & 16 \\
\hline
\end{tabular}

Barrel adalah salah satu bagian dari mesin extruder dengan salah satu komponen utamanya adalah screw, umumnya terdiri dari 3 zona yaitu zona feeding, zona melting, zona metering. Zona feeding adalah zona dimana material padat dalam bentuk butiran atau bubuk didorong dan dilembutkan menuju zona berikutnya, panas pada zona ini bersumber dari temperatur barrel area 1 . Zona melting atau zona transisi adalah zona dimana material mulai mencair sampai dengan mencair sempurna secara bertahap, dibutuhkan pengaturan temperatur sepanjang pergerakan molten, panas pada zona ini bersumber dari temperatur barrel area 1, 2 dan 3. Zona metering adalah zona dimana molten siap didorong ke luar screw melalui die, panas pada zona ini bersumber dari temperatur area 3 dan 4 . Hubungan area setting temperatur barrel dengan masing-masing zona pada penelitiaan ini diilustrasikan seperti Gambar 1. 


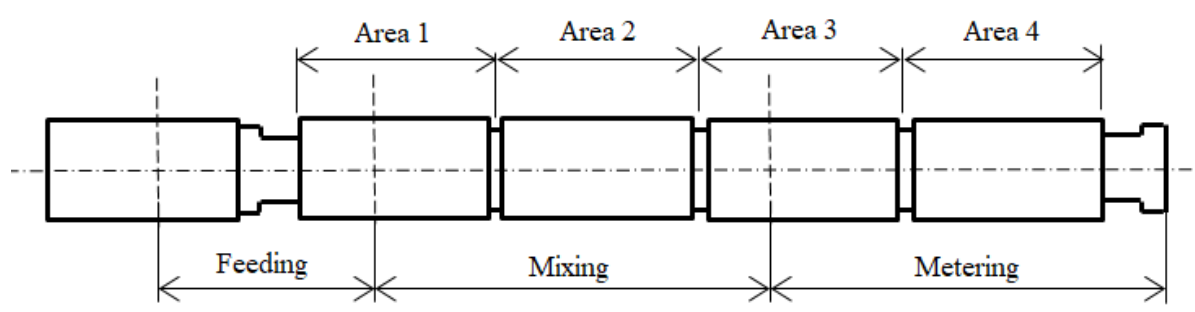

Gambar 1. Ilustrasi hubungan zona dan area setting temperatur barrel

Tahapan ketiga adalah menentukan orthogonal array (OA) yang merupakan dasar dari analisis eksperimen dari metode Taguchi, digunakan untuk mengurangi jumlah eksperimen (Mariajayaprakash dan Senthilvelan, 2013). Dengan jumlah faktor sebanyak 5 dan banyak level masing-masing faktor ada 3, maka orthogonal array $L_{27}\left(3^{5}\right)$ (Alafaghani dan Qattawi, 2018) dipilih pada penelitian ini.

Pada tahap eksperimen, kondisi setting mesin masing-masing eksperimen mengikuti Tabel 3. Pada setiap eksperimen, ambil sampel sebanyak 12 batang untuk dilakukan pengujian, untuk mengetahui atribut produk, yaitu ketahanan pipa terhadap beban kejut (impact strength).

Tahap berikutnya adalah pengujian sampel dengan prosedur impact test mengikuti standar BS EN 61386-1: 2008 pada poin 10.3. Satu batang pipa dipotong menjadi 3 bagian, diambil dari kedua ujung pipa dan tengah, dengan panjang masing-masing $\pm 20 \mathrm{~cm}$, masukkan kedalam refrigerator dengan suhu $-5^{\circ} \mathrm{C}^{ \pm 2}$ selama \pm 30 menit, lalu pasang sampel pada alat uji seperti terlihat pada Gambar 2.

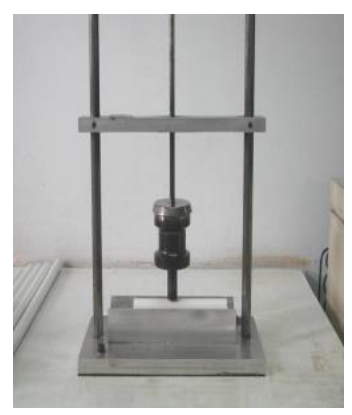

Gambar 2. Alat uji impact test

Jatuhkan beban seberat $2 \mathrm{~kg}$ dari ketinggian $300 \mathrm{~mm} \pm 1$ lalu periksa kondisi pipa, apakah pecah (NG) seperti pada Gambar 3, catat jumlah yang pecah dan hitung persentasenya.

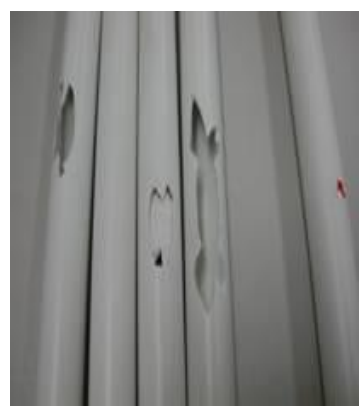

Gambar 3. Pipa pecah (NG) hasil pengujian 
Tabel 3. Setting mesin sesuai standar orthogonal array $\left(\mathrm{L}_{27}\right) 3^{5}$

\begin{tabular}{cccccc}
\hline \multirow{2}{*}{ No. Eksperimen } & \multicolumn{4}{c}{ Temp. Barrel $\left({ }^{\circ} \mathrm{C}\right)$} & \multirow{2}{*}{$\begin{array}{c}\text { Kecepatan } \\
\text { screw }(\text { RPM })\end{array}$} \\
\cline { 2 - 5 } 1 & Area 1 & Area 2 & Area 3 & Area 4 & 14 \\
2 & 180 & 190 & 160 & 165 & 15 \\
3 & 180 & 190 & 160 & 165 & 16 \\
4 & 180 & 190 & 160 & 165 & 14 \\
5 & 180 & 195 & 165 & 175 & 15 \\
6 & 180 & 195 & 165 & 175 & 16 \\
7 & 180 & 195 & 165 & 175 & 14 \\
8 & 180 & 200 & 175 & 180 & 15 \\
9 & 180 & 200 & 175 & 180 & 16 \\
10 & 180 & 200 & 175 & 180 & 14 \\
11 & 185 & 190 & 165 & 180 & 15 \\
12 & 185 & 190 & 165 & 180 & 16 \\
13 & 185 & 190 & 165 & 180 & 14 \\
14 & 185 & 195 & 175 & 165 & 15 \\
15 & 185 & 195 & 175 & 165 & 16 \\
16 & 185 & 195 & 175 & 165 & 15 \\
17 & 185 & 200 & 160 & 175 & 16 \\
18 & 185 & 200 & 160 & 175 & 14 \\
19 & 185 & 200 & 160 & 175 & 15 \\
20 & 190 & 190 & 175 & 175 & 16 \\
21 & 190 & 190 & 175 & 175 & 14 \\
22 & 190 & 190 & 175 & 175 & 16 \\
23 & 190 & 195 & 160 & 180 & 16 \\
24 & 190 & 195 & 160 & 180 & 160 \\
25 & 190 & 195 & 160 & 180 & 165 \\
26 & 190 & 200 & 165 & 165 & 165 \\
27 & 190 & 200 & 165 & 165 & \\
\hline
\end{tabular}

Analisis data hasil pengujian dilakukan untuk menentukan Signal to noise ratio ( $\mathrm{S} / \mathrm{N}$ ratio) sebagai nilai dari karakteristik mutu atau parameter proses (Tsai, 2011), nilai $\mathrm{S} / \mathrm{N}$ ratio tertinggi merupakan kombinasi faktor-level yang paling optimum (Sharma et al., 2017). Secara umum, terdapat 3 jenis karakteristik performa yang menjadi dasar perhitungan nilai $\mathrm{S} / \mathrm{N}$ ratio, yaitu smaller the better, larger the better, nominal the better (Liu et al., 2019). Respon dari desain experiment penelitian ini adalah data terkait dengan persentase pipa pecah, maka karakteristik performa smaller the better yang dipilih. Data hasil eksperimen juga dianalisa dengan ANOVA, untuk mengetahui pengaruh masing-masing faktor terhadap respon (Kumar et al., 2016), dan penelitian ini menetapkan nilai a adalah 0,05.

\section{HASIL DAN PEMBAHASAN}

Dari eksperimen dan pengujian yang dilakukan terhadap sampel sebanyak 12 batang yang dipotong menjadi 3 bagian sepanjang $20 \mathrm{~cm}$, berikut hasil pengolahan data menggunakan program Minitab 19, seperti terlihat pada Gambarl 4 berikut ini. 


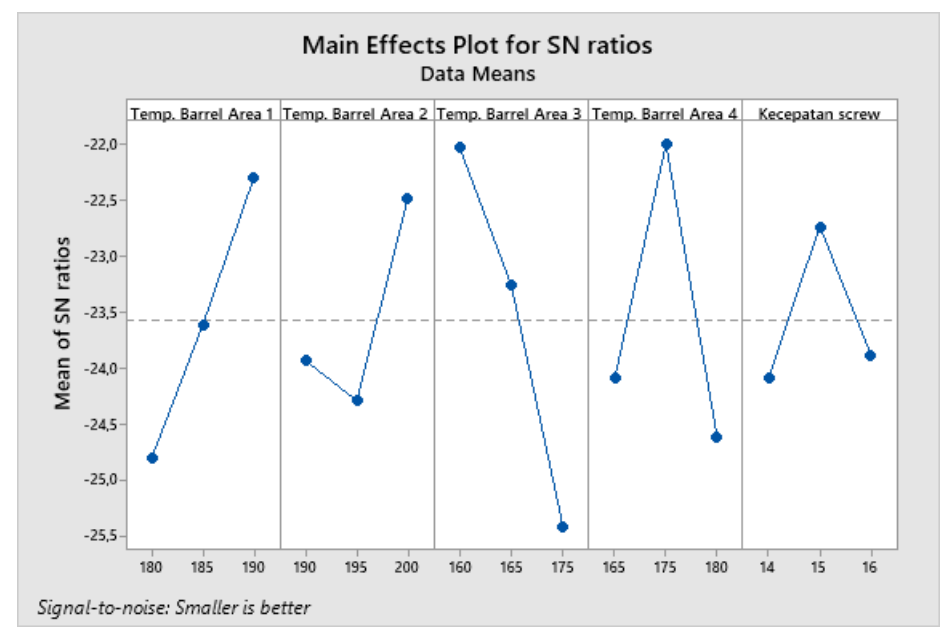

Gambar 4. Nilai s/n ratio untuk setiap faktor dengan masing-masing level

Nilai yang paling optimal pada setiap faktor adalah nilai SN ratio tertinggi diantara levelnya, sehingga berdasarkan Gambar 4, dapat disusun kombinasi optimal faktor-level yaitu $A_{3} B_{3} C_{1} D_{2} E_{2}$ seperti terlihat pada Tabel 4.

Tabel 4. Kombinasi faktor-level optimal

\begin{tabular}{cccc}
\hline & Faktor & Level & Nilai \\
\hline A & Temp. Barel Area 1 $\left({ }^{\circ} \mathrm{C}\right)$ & 3 & 190 \\
B & Temp. Barel Area 2 $\left({ }^{\circ} \mathrm{C}\right)$ & 3 & 200 \\
C & Temp. Barel Area 3 $\left({ }^{\circ} \mathrm{C}\right)$ & 1 & 160 \\
D & Temp. Barel Area 4 $\left({ }^{\circ} \mathrm{C}\right)$ & 2 & 175 \\
E & Kecepatan screw $($ RPM $)$ & 2 & 15 \\
\hline
\end{tabular}

Tabel 5. Hasil analysis of variance

\begin{tabular}{ccccccc}
\hline Faktor & DF & Contribution & Adj SS & Adj MS & F & P \\
\hline A & 2 & $10,56 \%$ & 90,40 & 45,202 & 1,85 & 0,189 \\
B & 2 & $7,89 \%$ & 67,56 & 33,781 & 1,38 & 0,279 \\
C & 2 & $25,48 \%$ & 218,06 & 109,028 & 4,47 & 0,029 \\
D & 2 & $8,65 \%$ & 74,01 & 37,006 & 1,52 & 0,250 \\
E & 2 & $1,78 \%$ & 15,23 & 7,616 & 0,31 & 0,736 \\
Error & 16 & $45,64 \%$ & 390,59 & 24,412 & & \\
Total & 26 & $100,00 \%$ & & & & \\
\hline
\end{tabular}

Tampak pada Tabel 5 bahwa nilai $p$ dari faktor $A$ adalah 0,189, lebih besar dari a, dapat disimpulkan bahwa pada range antara $180^{\circ} \mathrm{C}-190^{\circ} \mathrm{C}$, perubahan temperatur di dalam range tersebut tidak berpengaruh pada persentase pipa pecah, dan nilai optimal adalah $190^{\circ} \mathrm{C}$. Nilai $\mathrm{p}$ dari faktor $\mathrm{B}$ adalah 0,279, lebih besar dari $\mathrm{a}$, dapat disimpulkan bahwa pada range antara $190^{\circ} \mathrm{C}-200^{\circ} \mathrm{C}$, perubahan temperatur di dalam range tersebut tidak berpengaruh pada persentase pipa pecah, dan $200^{\circ} \mathrm{C}$ adalah temperatur yang optimal. Nilai $\mathrm{p}$ dari faktor $\mathrm{C}$ adalah 0,029 , lebih kecil dari a, dapat disimpulkan bahwa pada range antara $160^{\circ} \mathrm{C}-175^{\circ} \mathrm{C}$, perubahan temperatur di dalam range tersebut berpengaruh pada persentase pipa pecah, dan temperatur 
$160^{\circ} \mathrm{C}$ adalah temperatur yang optimal. Nilai $\mathrm{p}$ dari faktor $\mathrm{D}$ adalah 0,250 , lebih besar dari $\mathrm{a}$, dapat disimpulkan bahwa pada range antara $165^{\circ} \mathrm{C}-180^{\circ} \mathrm{C}$, perubahan temperatur di dalam range tersebut tidak berpengaruh pada persentase pipa pecah, dan temperatur $175^{\circ} \mathrm{C}$ adalah temperatur yang optimal. Nilai $p$ dari faktor $E$ adalah 0,736 , lebih besar dari $a$, dapat disimpulkan bahwa pada range antara 14 RPM - 16 RPM, perubahan kecepatan screw dalam range tersebut tidak berpengaruh pada persentase pipa pecah, dan kecepatan 15 RPM adalah kecepatan yang optimal.

Pada zona feeding, dengan tidak adanya pengaruh perubahan temperatur barrel area 1 (faktor A), menunjukkan perubahan ini tidak berakibat terjadinya perubahan karakteristik proses di dalam barre/ yang dapat mendegradasi mutu material sehingga berakibat pipa pecah. Pada zona mixing, perubahan temperatur barrel area 1 (faktor A) dan temperatur barrel area 2 (faktor B), keduanya juga tidak membuat terjadinya degradasi mutu material sehingga berakibat pipa pecah. Namun sebaliknya, teridentifikasi bahwa perubahan temperatur pada area 3 (faktor C) berakibat terjadinya perubahan karakteristik proses di dalam barre/ yang dapat mendegradasi mutu material. Pada zona metering, sama seperti pada zona mixing, teridentifikasi bahwa perubahan temperatur area 3 (faktor $\mathrm{C}$ ) dapat membuat terjadi degradasi mutu material, temuan penelitian ini mengkonfirmasi penelitian terdahulu bahwa temperatur zona metering adalah yang paling signifikan di antara temperatur zona barrel (Abeykoon et al., 2013), sementara perubahan temperatur pada area 4 (faktor D) tidak membuat terjadinya degradasi material.

\section{KESIMPULAN}

Dari perhitungan $\mathrm{S} / \mathrm{N}$ ratio diperoleh parameter optimal yaitu $190^{\circ} \mathrm{C}$ untuk faktor $\mathrm{A}, 200^{\circ} \mathrm{C}$ untuk faktor $\mathrm{B}, 160^{\circ} \mathrm{C}$ untuk faktor $\mathrm{C}, 175^{\circ} \mathrm{C}$ untuk faktor $\mathrm{D}$ dan $15 \mathrm{RPM}$ untuk faktor $\mathrm{E}$, dapat disingkat menjadi $A_{3} B_{3} C_{1} D_{2} E_{2}$. Sementara itu, dari analisis Anova dapat diidentifikasi bahwa faktor $\mathrm{C}$ atau temperatur barrel area 3 menjadi parameter yang kritis, perubahan pada temperatur akan berdampak pada perubahan karakteristik proses yang terjadi di dalam barrel, baik pada zona mixing atau zona metering atau pada keduanya.

\section{DAFTAR PUSTAKA}

Abeykoon, C., Adrian L. K., Peter J.M., Kang., L. 2013. Dynamic modelling of die melt temperature profile in polymer extrusion. Proceedings of the IEEE Conference on Decision and Control July 2014: 2550-2555.

Alafaghani, A. dan Qattawi, A. 2018. Investigating the effect of fused deposition modeling processing parameters using Taguchi design of experiment method. Journal of Manufacturing Processes 36(December): 164-174.

Balaram Naik, A. dan A. Chennakeshava R. 2018. Optimization of tensile strength in TIG welding using the Taguchi method and analysis of variance (ANOVA). Thermal Science and Engineering Progress 8(August): 327-339.

Banker, R. D., Mashruwala, R. dan Tripathy, A. 2014. Does a differentiation strategy lead to more sustainable financial performance than a cost leadership strategy?. Management Decision 52(5): 872-896.

BS EN 61386-1. 2008. Specification for Conduit systems for cable management.

Chen, H. J., Chang, S. N. dan Tang, C. W. 2017. Application of the Taguchi method for optimizing the process parameters of producing lightweight aggregates by incorporating tile grinding sludge with reservoir sediments. Materials 10(11) 
Chenthamarakshan, A., Nayana. P., Nafeesathul, M., P. S. Soumya, M. S. Kiran. L., Anala, R., Anuja, D., dan Padma, N. 2017. Optimization of laccase production from Marasmiellus palmivorus LA1 by Taguchi method of Design of experiments. BMC Biotechnology 17(1): $1-11$.

Fatah, K.M.A. 2020. Analisis Unjuk Kerja Oven Pengering Hasil Modifikasi Dengan Variasi Kecepatan Aliran Udara Panas. Jurnal Infotekmesin 11(02): 153-157.

Gadekar, M. S. S., Khan, J. G. dan Dalu, R. S. 2015. Analysis of Process Parameters for Optimization of Plastic Extrusion in Pipe Manufacturing. International Journal of Engineering Research and Applications 5(5): 71-74.

González-Seligra, P., Lucas. G., Oswaldo, O., Silvia, G., dan Lucía, F. 2017. Influence of extrusion process conditions on starch film morphology. Lwt 84: 520-528.

Holsopple, P. S. 1993. The advantages of one pack additive packages in PVC processing', Journal of Vinyl Technology 15(1): 2-8.

Jiang, Z., Jingwen, W., Renkui, G., dan Chanjun, W. 2018. The effects of surface modification of ground calcium carbonate powdery fillers on the properties of PVC. Polymer Bulletin 75(3): 1123-1139.

Joshi, R. dan Goyal, S. 2018. Quality Assurance in High Density Plastic Pipes Manufacturing Process by Taguchi Approach. International Research Journal of Engineering and Technology 5(12): 574-579.

Khanna, N. dan Davim, J. P. 2015. Design-of-experiments application in machining titanium alloys for aerospace structural components', Measurement: Journal of the International Measurement Confederation 61: 280-290.

Kumar, N., Kumar, H. dan Khurmi, J. S. 2016. Experimental Investigation of Process Parameters for Rapid Prototyping Technique (Selective Laser Sintering) to Enhance the Part Quality of Prototype by Taguchi Method. Procedia Technology 23: 352-360

Liang, J. Z., Li, R. K. Y. dan Tjong, S. C. 1999. Effects of pressure and temperature on the melt density. Journal of Materials Processing Technology 91: 167-171.

Liu, X., Yuekuan, Z., Chun Qing, L., Yaolin, L., Wei, Y., Guoqiang, Z. 2019. Optimization of a new phase change material integrated photovoltaic/thermal panel with the active cooling technique using taguchi method. Energies 12(6): 1-22.

Magnago, R. F., N. Dayane, M., Mayara, M., H. R. Turatti, S., Paola, E., dan Luciano, S. (2017). Investigating the influence of conduit residues on polyurethane plates. Polimeros 27(2): 141-150.

Mariajayaprakash, A. dan Senthilvelan, T. 2013. Failure detection and optimization of sugar mill boiler using FMEA and Taguchi method. Engineering Failure Analysis 30: 17-26.

Moralı, U., Demiral, H. dan Şensöz, S. 2018. Optimization of activated carbon production from sunflower seed extracted meal: Taguchi design of experiment approach and analysis of variance. Journal of Cleaner Production 189: 602-611.

Natalia, I.E. 2019 Strategies To Achieve Competitive Advantage In Industrial Revolution 4.0. International Journal of Research Culture Society 3(6): 10-16.

Pang, J.S., , M.N.M. Ansari, Omar S.Z., Moaz H.A., dan S.M. Pang. S. 2014. Taguchi design optimization of machining parameters on the CNC end milling process of halloysite nanotube with aluminium reinforced epoxy matrix (HNT/Al/Ep) hybrid composite', HBRC Journal 10(2): 138-144.

Rao, S., Pragati, S., Athira, K., dan Reshma, S. 2013. An Overview of Taguchi Method: Evolution, Concept and Interdisciplinary Applications. International Journal of Scientific \& 
Engineering Research, 4(10): 621-626.

Sharma, G. V. S. S., Rao, R. U. dan Rao, P. S. 2017. A Taguchi approach on optimal process control parameters for HDPE pipe extrusion process. Journal of Industrial Engineering International 13(2): 215-228.

Shrestha, S. dan Manogharan, G. 2017. Optimization of Binder Jetting Using Taguchi Method. Jom 69(3): 491-497.

Solomon K., N. Srirangarajalu dan Assefa Asmare. 2016. Parameter Optimization of Extrusion Machine Producing UPVC Pipes using Taguchi Method: A Case of Amhara Pipe Factory. International Journal of Engineering Research and Technology 5(01): 65-75.

Song, J., Fei, D., Jiwen, Z., Siliang, L., Shaokun, D., dan Hui, W. 2017. Optimal design of permanent magnet linear synchronous motors based on Taguchi method. IET Electric Power Applications 11(1): 41-48.

Tsai, T. N. 2011. Improving the fine-pitch stencil printing capability using the Taguchi method and Taguchi fuzzy-based model. Robotics and Computer-Integrated Manufacturing 27(4): 808-817.

Yizong, T., Ariff, Z. M., dan Khalil, A. M. 2017. Influence of Processing Parameters on Injection Molded Polystyrene Using Taguchi Method as Design of Experiment. Procedia Engineering 184: 350-359. 